Technological University Dublin

DÜBLIN

ARROW@TU Dublin

2009-01-01

\title{
A Printed CPW-Fed Slot-Loop Antenna with Narrowband Omnidirectional Features
}

\author{
S. Shynu \\ Technological University Dublin \\ Max Ammann \\ Technological University Dublin, max.ammann@tudublin.ie
}

Follow this and additional works at: https://arrow.tudublin.ie/engscheceart

\section{Recommended Citation}

Shynu, S. \& Amman, M. (2009) A Printed CPW-Fed Slot-Loop Antenna with Narrowband Omnidirectional Features. IET Microwaves, Antennas and Propagation, vol.3, no. 4, 2009, pp.673-680. doi:10.1049/ietmap.2008.0198

This Article is brought to you for free and open access by the School of Electrical and Electronic Engineering at ARROW@TU Dublin. It has been accepted for inclusion in Articles by an authorized administrator of ARROW@TU Dublin. For more information, please contact arrow.admin@tudublin.ie, aisling.coyne@tudublin.ie, gerard.connolly@tudublin.ie.

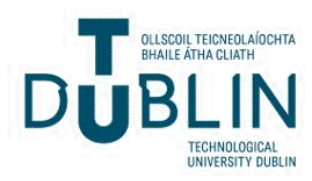




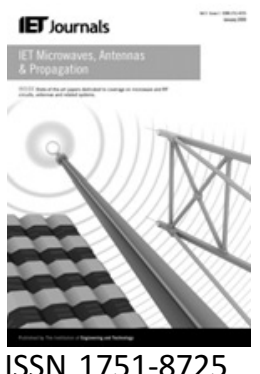

\title{
A printed CPW-fed slot-loop antenna with narrowband omnidirectional features
}

\author{
S.V. Shynu M.J. Ammann
}

\author{
School of Electronic and Communications Engineering, Dublin Institute of Technology, Dublin 8, Ireland \\ E-mail: max.ammann@dit.ie
}

\begin{abstract}
The design of a novel CPW-fed printed slot-loop antenna with narrowband omnidirectional attributes is proposed. The antenna geometry is selected to reduce slot coupling, thus achieving both a narrow bandwidth and an omnidirectional radiation pattern simultaneously. A gain of $2.1 \mathrm{dBi}$ is accomplished with high radiation efficiency. Very narrow fractional impedance bandwidths as low as $2.9 \%$ are realised with good omnidirectional radiation characteristics. A technique providing unconstrained control of the bandwidth in the range of $1.7-6.9 \%$ is described.
\end{abstract}

\section{Introduction}

The sustained miniaturisation of electronic devices demands continued reduction in antenna size and profile. Studies have been carried out to determine how small an antenna can be, while maintaining high gain and bandwidth [1-4]. However, very few studies were carried out to design narrowband omnidirectional microstrip antennas with reasonable gain and high radiation efficiency. Narrow bandwidths are desirable in many applications such as in security and military systems, radiolocation, low power devices and digital enhanced cordless telecommunications (DECT), where system selectivity can be improved. Many military security communication systems prefer neighbouring antennas with high mismatch loss and decoupling preferably achieved by narrowband antennas $[5,6]$. At present, complex impedance structures are needed to achieve good decoupling between omnidirectional antennas located in close proximity [7]. Omnidirectional printed antenna designs using CPW feed methods have been reported [8-10]. The printed loop antenna with a uniform current distribution is a suitable choice for omnidirectional radiation pattern. However, a small loop antenna with low radiation resistance and high reactance is difficult for impedance match. Although a larger loop antenna has a reasonable radiation resistance, the antenna current distribution along the loop becomes non-uniform and thus will not yield the desired omnidirectional pattern. To design a loop antenna with an omnidirectional radiation pattern with an acceptable input impedance matching is challenging. A modified Alford open-loop antenna was proposed for omnidirectional radiation patterns in $2.4 \mathrm{GHz}$ applications but with significantly lower gain and broader impedance bandwidth [11]. These omnidirectional antennas have broad impedance bandwidths, greater than $10 \%$, which makes them inappropriate for narrowband applications [12]. No studies were reported to design narrowband omnidirectional microstrip antennas. The bandwidth of printed slot-loop antennas is increased at the cost of gain and directivity. That is, the smaller the bandwidth, the more directional the radiation becomes, with reduced beamwidth. In general, if a printed slot-loop antenna becomes omnidirectional, its bandwidth tends to become wider and gain deteriorates [13]. Therefore, physically, it is not easy to design an antenna with omnidirectional radiation pattern and narrow bandwidth, while maintaining reasonable gain. Microstrip slot-loop antennas have the advantage of being able to produce bidirectional and unidirectional radiation patterns with impedance bandwidths ranging from $10 \%$ to $70 \%$. An interesting feature of slot antennas is this greater bandwidth because of the bidirectional radiation properties. But normal microstrip slot antennas are not compatible with monolithic fabrication and therefore easier integration with active solid state devices is not possible. CPW-fed slot antennas can solve these problems effectively [14-16].

In this paper, a novel design of a compact CPW-fed slotloop antenna that provides both omnidirectional and 
narrowband characteristics is presented. The high crosspolarisation level typically seen in these types of slot-loop antennas is reduced in the proposed antenna. As maintaining a very good radiation efficiency and reasonable gain for a narrowband omnidirectional antenna is difficult, the design considerations made to implement this are described in the paper. Furthermore, good control of the antenna bandwidth is realised by varying the width of the radiating slot, without significantly affecting the antenna input impedance or resonant frequency.

\section{Antenna design}

Normal slot-loop configurations with CPW feeds require a long CPW transmission line to match the loop (owing to orthogonality of the feedline with respect to the loop long dimension), resulting in larger antenna size. Moreover, the large horizontal dimension of these loops limits the modification of the bidirectional radiation pattern of the slot-loop antenna into an omnidirectional one [17]. As the antenna operating frequency mainly depends on the total slot-loop length, $2(l+w)$, feeding it along the smaller dimension (width) of the loop with a tuning stub provides a better way to realise compactness and omnidirectionality. The operating bandwidth and the symmetry of the pattern depends mainly on the aspect ratio of the loop, which is given by $\gamma=l / w$. A square loop $(\gamma=1)$ shows better symmetry of the bidirectional radiation patterns, but has a narrower band in terms of matching than a loop having a smaller aspect ratio. Therefore, a much greater aspect ratio has been chosen in this design to favour narrowband omnidirectional design. Furthermore, for slot-loop antenna designs with $\gamma<1$, there is an abrupt rise in the input impedance close to the resonant frequency, as the width $\left(w_{s}\right)$ of the radiating slot increases [18]. This effect is significantly reduced with the appropriate selection of the aspect ratio in the proposed design.

The geometry of the proposed narrowband omnidirectional slot-loop antenna is shown in Fig. 1. The CPW arrangement employs single-sided laminate in order to realise an omnidirectional pattern. The CPW feedline is designed for $50 \Omega$ characteristic impedance using Agilent AppCAD and optimised with CST Microwave Studio. The CPW centre strip has a width of $w_{c}=6.4 \mathrm{~mm}$ and gap of $g_{c}=0.5 \mathrm{~mm}$. The antenna is fabricated on an FR-4 substrate with dielectric constant, $\varepsilon_{r}=4.1$ and thickness $h=1.52 \mathrm{~mm}$. AS there is a linear relationship between the total slot-loop length and the dominant resonant mode, the slot-loop length, $l$ is chosen slightly less than one-half of the slot wavelength $\left(l \approx 0.82 \lambda_{s} / 2\right)$. The slot-loop width, $w$ is kept less than one-quarter of $\lambda_{s}\left(w \approx 0.62 \lambda_{s} / 4\right)$ to minimise the magnetic current variation along the loop width, w. However, the slot-loop width is critical for impedance matching. The groundplane dimensions also affect the antenna input impedance and it is found that the groundplane width $W$ must be optimised for good

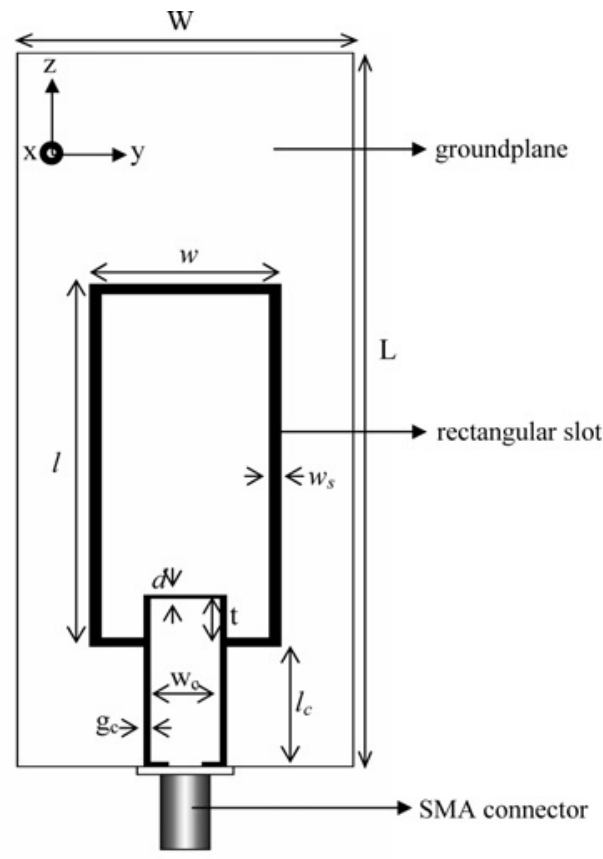

Figure 1 Geometry of the proposed CPW fed slot-loop antenna

The various dimensions in $\mathrm{mm}$ are: $L=86, W=30, w=16$, $I=42.5, w_{\mathrm{s}}=0.5, w_{\mathrm{c}}=6.4, I_{\mathrm{c}}=14.55, g_{\mathrm{c}}=0.5, t=4.05$ and $d=0.3$

impedance matching. The optimised groundplane dimensions are $L=86 \mathrm{~mm}$ and $W=30 \mathrm{~mm}$.

A new type of inset CPW feeding with a tuning stub is introduced to improve matching at the resonant frequency. The tuning stub length, $t$ is $4.05 \mathrm{~mm}$ with a top slot gap, $d=0.3 \mathrm{~mm}$. The antenna bandwidth shows dependence on both the tuning stub length and the top slot width and therefore some fine tuning is needed to achieve narrow bandwidth. The geometry of the slot is different from that

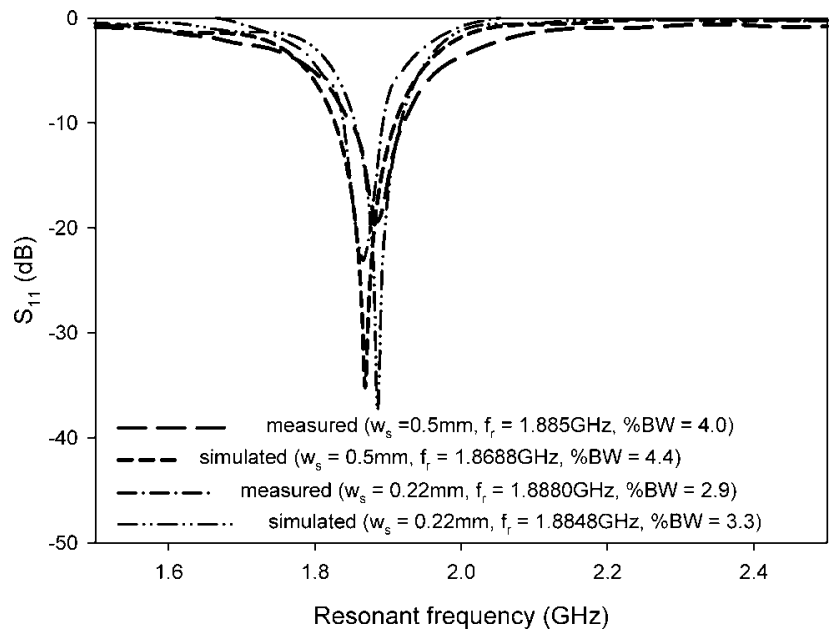

Figure 2 The measured and simulated $S_{11}$ of the proposed narrowband omnidirectional CPW fed slot-loop antenna for a slot width, $w_{s}=0.5$ and $0.22 \mathrm{~mm}$ 


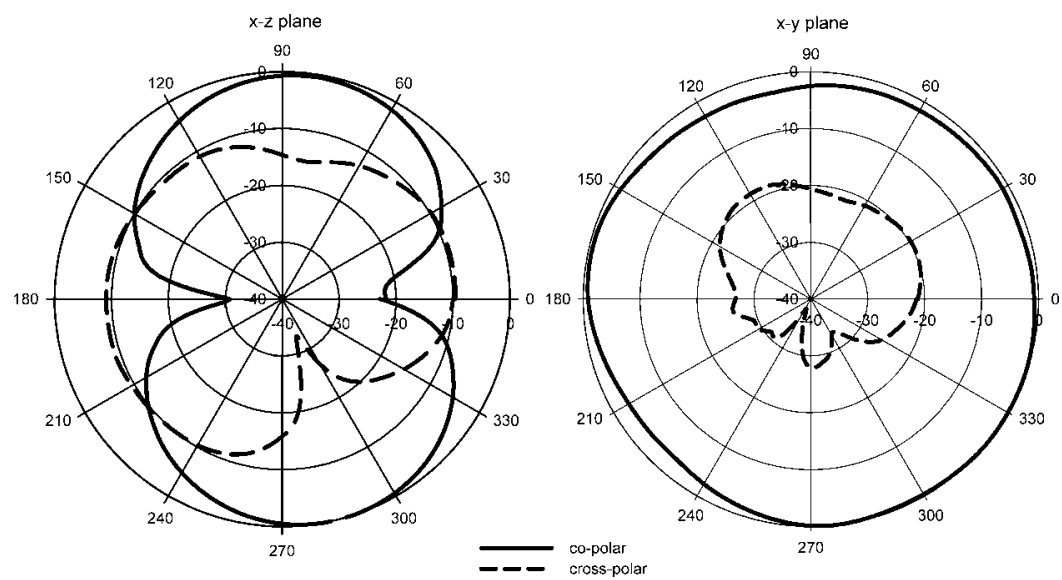

Figure 3 Measured far-field co-polar and cross-polar radiation patterns of the CPW fed slot-loop antenna at $1.885 \mathrm{GHz}$

of the conventional slot-loop CPW antennas and the slotloop length; $l$ is much larger compared with the slot-loop width $w$, giving an aspect ratio, $\gamma=2.65$. This significantly reduces the coupling from the horizontal and vertical slots along the width and length of the rectangular slot and effectively decreases the antenna bandwidth.

The measured and simulated $S_{11}$ of the proposed antenna for a slot width $w_{s}=0.5 \mathrm{~mm}$ and $0.22 \mathrm{~mm}$ is illustrated in Fig. 2, showing good agreement. It is observed that for $w_{s}=0.22 \mathrm{~mm}$, the antenna resonates at $1.8880 \mathrm{GHz}$ with a $10 \mathrm{~dB}$ RL impedance bandwidth of $55 \mathrm{MHz}$ that corresponds to a narrow fractional bandwidth of $2.9 \%$. The measured $S_{11}$ clearly shows that unlike other slot-loop designs, the proposed antenna operates in a narrower band with good impedance matching. The bandwidths of ordinary slot-loop antennas range from $6 \%$ to $7 \%$ with the bidirectional radiation pattern. This bandwidth will broaden again if an omnidirectional pattern is required. The measured antenna gain was found to be $2.1 \mathrm{dBi}$ and the simulated radiation efficiency was $93 \%$.

The measured radiation patterns for the two principal planes are plotted in Fig. 3. The design provides an omnidirectional radiation pattern, superior to that of the conventional slot-loop antennas, with an average pattern variation of $1.5 \mathrm{~dB}$ in the $x y$-plane. By choosing a large aspect ratio for the loop and hence a small slot loop width $w$, the radiated electric fields in the azimuth plane (xy-plane) of the proposed antenna are aligned along the direction of the current (along $z$-axis). The spacing of the excited surface currents on the two side edges of the antenna is electrically too small to allow asymmetry in the azimuthal pattern. The level of cross-polarisation in normal CPW-fed slot-loop antennas is very high [19]. The crosspolarisation mainly arises from the sides of the loop parallel

Table 1 Performance of the proposed CPW fed slot-loop antenna with various rectangular slot-loop dimensions

\begin{tabular}{|c|c|c|c|c|c|c|}
\hline $\begin{array}{l}\text { Slot-loop width, w } \\
(\mathrm{mm})\end{array}$ & $\begin{array}{l}\text { Slot-loop length, } \\
\qquad /(\mathrm{mm})\end{array}$ & $\begin{array}{l}\text { Resonant } \\
\text { frequency } \\
\quad(\mathrm{GHz})\end{array}$ & Bandwidth $(\mathrm{MHz})$ & $\%$ bandwidth & Gain $(\mathrm{dBi})$ & Rad. eff. (\%) \\
\hline \multirow[t]{5}{*}{16} & 34.5 & 2.1696 & 97.9 & 4.4 & 2.6 & 92.8 \\
\hline & 38.5 & 2.0192 & 101.3 & 5.0 & 2.3 & 93.5 \\
\hline & 42.5 & 1.8848 & 98.8 & 5.2 & 2.1 & 93.0 \\
\hline & 46.5 & 1.7631 & 92.0 & 5.2 & 2.0 & 91.4 \\
\hline & 48.5 & 1.7088 & 85.4 & 5.0 & 1.9 & 91.1 \\
\hline 12 & \multirow[t]{5}{*}{42.5} & 1.9840 & - & - & 2.0 & 90.0 \\
\hline 14 & & 1.9328 & 74.9 & 3.9 & 2.0 & 90.6 \\
\hline 16 & & 1.8848 & 98.8 & 5.2 & 2.1 & 93.0 \\
\hline 18 & & 1.8337 & 100.3 & 5.5 & 2.1 & 93.6 \\
\hline 20 & & 1.7868 & - & - & 2.1 & 94.0 \\
\hline
\end{tabular}

The fixed dimensions are: $L=86, W=30, w_{s}=0.5, w_{c}=6.4, I_{c}=14.55, g_{c}=0.5, t=4.05$ and $d=0.3$ 


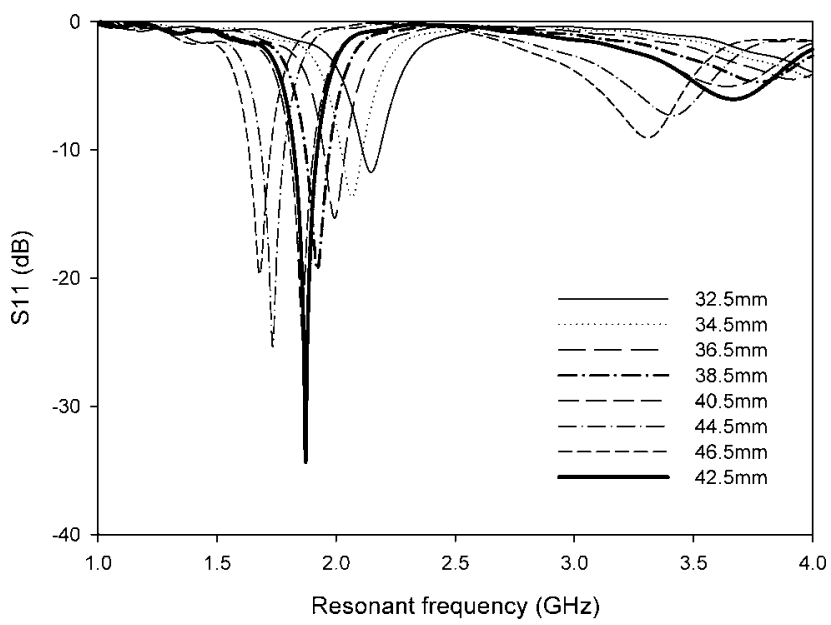

a

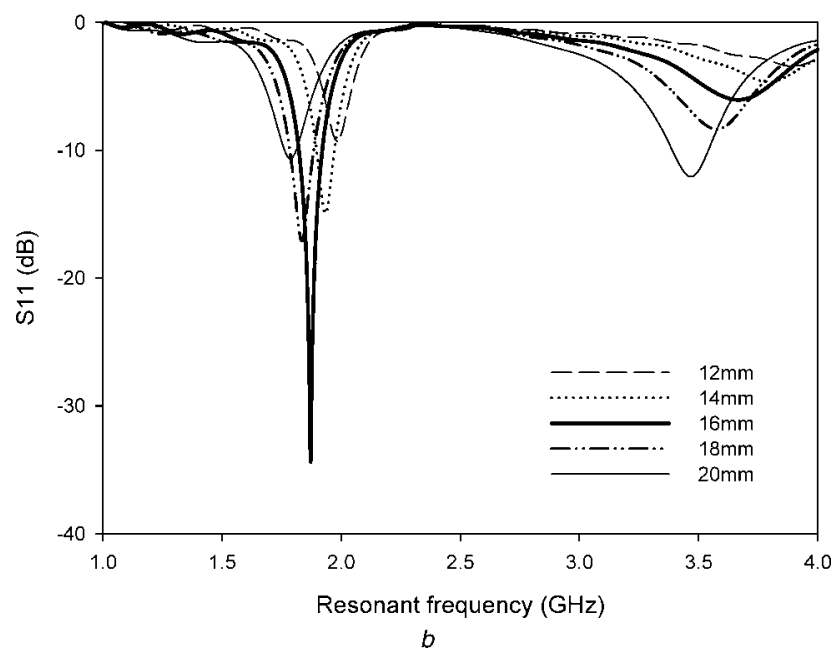

Figure 4 Variation of resonant frequency and S11 with different slot-loop dimensions

a With slot-loop length, I

$b$ With slot-loop width, $w$

to the CPW feedline. But this cross-polarisation can be reduced by increasing the length $l$ of the slot-loop. The field distribution is weaker when the slot-loop length, $l$ is increased. By suitably selecting the aspect ratio for the rectangular slot-loop, this high level of cross-polarisation is reduced along the $z$-axis in the $x-z$ plane to better than $-15 \mathrm{~dB}$ in the proposed design.

\section{Parametric studies and discussion}

An important goal of this paper is to provide design information for the narrowband omnidirectional CPW-fed microstrip antenna. Rigorous parametric studies are carried out to investigate the effect of antenna geometry on the input impedance, resonant frequency, bandwidth, gain, radiation efficiency and level of cross-polarisation. The criteria to obtain a good omnidirectional radiation pattern are also discussed.

\subsection{Effect of rectangular slot-loop dimensions (I and $w$ )}

The resonant frequency of the proposed slot-loop antenna depends on the total slot-loop length $2(l+w)$. Considering the presence of different dielectric properties on either side of the slot and the fact that the field components are not confined to the dielectric substrate alone, the wavelength in the slot-loop may be calculated as

$$
\lambda_{s}=c / f_{r} \sqrt{ } \varepsilon_{r \text { eff }}
$$

where $\varepsilon_{r \text { eff }}$ is the effective dielectric constant given by $\varepsilon_{r \text { eff }}=\left(\epsilon_{r}+1\right) / 2$.

A design equation can then be derived empirically, relating the resonant frequency $\left(f_{r}\right)$ of slot-loop and the total slotloop length as

$$
f_{r}=1.14 c /\left\{2(l+w) \sqrt{ } \varepsilon_{r \text { eff }}\right\}
$$

Table 1 illustrates the variation in resonant frequency, fractional impedance bandwidth, gain and radiation efficiencies with change in slot dimensions. This has been studied by keeping the groundplane and tuning stub dimensions the same as described in Fig. 1. The variation of antenna resonant frequency with slot dimensions is plotted in Fig. 4. It is evident that the impedance matching of the antenna is heavily dependent on the slot-loop width, w. A similar observation is also made with the ground plane width $W$. Thus the dimensions of the antenna, orthogonal to the CPW feedline determine the impedance matching. The fractional impedance bandwidth shows an increase with increased slot-loop length $l$, while the gain decreases.

\subsection{Effect of groundplane dimension ( $L$ and $W$ )}

The width of the groundplane $W$ determines whether the radiation pattern of the proposed slot-loop antenna is omnidirectional or bidirectional in nature. Therefore the width of the groundplane is reduced to a minimum to yield better omnidirectional properties. But a reduction in the groundplane dimensions will increase the bandwidth. No significant reduction in antenna gain was observed when the ground plane dimension is changed. It was found that an increase in the groundplane width, $W$, affects the antenna's omnidirectional radiation pattern and for values greater than approximately $38 \mathrm{~mm}$, the pattern becomes essentially bidirectional. A decrease in bandwidth is observed with increase in groundplane width, accompanied by poor impedance matching. Hence, the groundplane width needs to be adjusted to provide better omnidirectional pattern and good matching. Table 2 tabulates the results for different values of $L$ and $W$ of the antenna for a particular slot loop and tuning stub dimension. No significant change in resonant frequency 
Table 2 Performance of the proposed CPW fed slot-loop antenna with different ground plane dimensions

\begin{tabular}{|c|c|c|c|c|c|c|}
\hline $\begin{array}{l}\text { Ground plane } \\
\text { width, } W(\mathrm{~mm})\end{array}$ & $\begin{array}{l}\text { Ground plane } \\
\text { length, } L(\mathrm{~mm})\end{array}$ & $\begin{array}{l}\text { Resonant frequency } \\
\qquad(\mathrm{GHz})\end{array}$ & $\begin{array}{l}\text { Bandwidth } \\
(\mathrm{MHz})\end{array}$ & $\%$ bandwidth & Gain (dBi) & Rad. eff. (\%) \\
\hline \multirow[t]{5}{*}{30} & 62 & 1.8368 & 126.8 & 6.9 & 2.3 & 94.7 \\
\hline & 70 & 1.8688 & 113.6 & 6.1 & 2.2 & 94.1 \\
\hline & 78 & 1.8848 & 104.8 & 5.6 & 2.1 & 92.8 \\
\hline & 86 & 1.8848 & 98.8 & 5.2 & 2.1 & 93.0 \\
\hline & 100 & 1.8752 & 77.7 & 4.1 & 2.3 & 90.4 \\
\hline 30 & \multirow[t]{5}{*}{86} & 1.8848 & 98.8 & 5.2 & 2.1 & 93.0 \\
\hline 34 & & 1.8816 & 88.7 & 4.7 & 2.0 & 90.7 \\
\hline 38 & & 1.8848 & 72.9 & 3.9 & 2.1 & 90.0 \\
\hline 42 & & 1.8847 & 51.5 & 2.7 & 2.3 & 91.7 \\
\hline 46 & & 1.8847 & 32.4 & 1.7 & 2.3 & 90.1 \\
\hline
\end{tabular}

The fixed dimensions in $\mathrm{mm}$ are: $l=42.5, w=16, w_{s}=0.5, w_{c}=6.4, I_{c}=14.55, g_{c}=0.5, t=4.05$ and $d=0.3$.

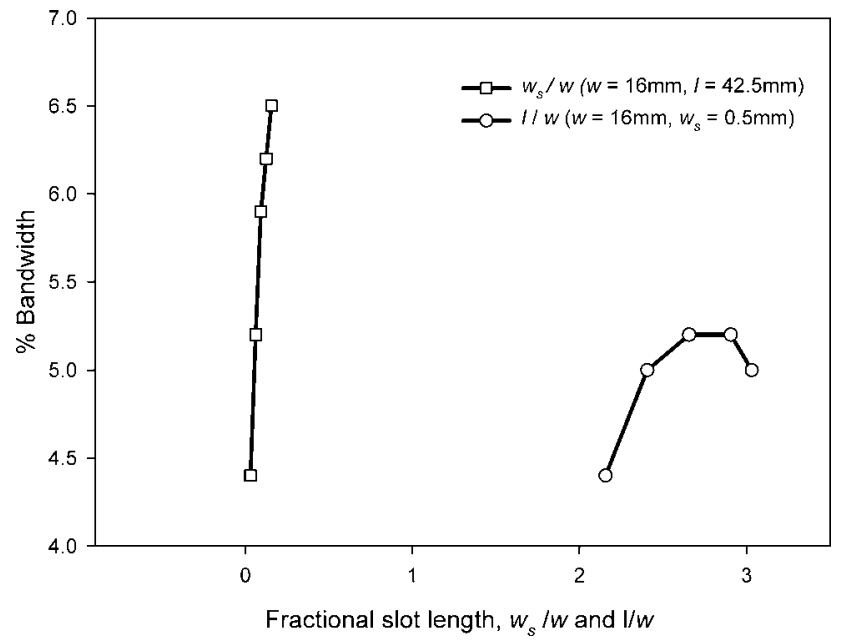

Figure 5 Effect of slot width, $w_{s}$, and slot-loop length, l, relative to the slot-loop width, $w$, on the percentage bandwidth of the antenna

All other antenna dimensions are the same as in Fig. 1

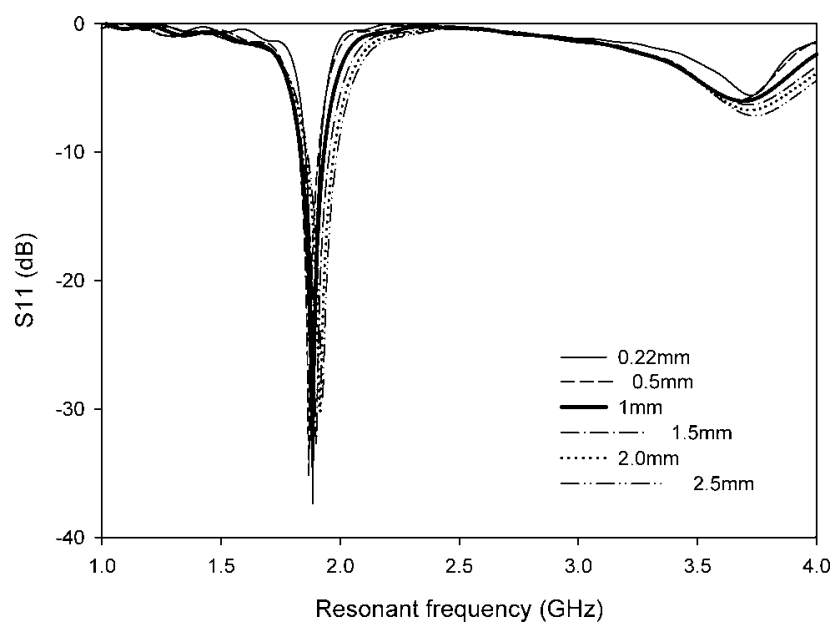

Figure $6 S_{11}$ of the proposed slot-loop antenna for different slot widths, $w_{s}$

Table 3 Performance of proposed CPW fed slot-loop antenna with change in slot width, $w_{s}$

\begin{tabular}{|c|c|c|c|c|c|c|c|}
\hline $\begin{array}{l}\text { Slot-loop width, } \\
w(\mathrm{~mm})\end{array}$ & $\begin{array}{c}\text { Slot-loop } \\
\text { length, I } \\
(\mathrm{mm})\end{array}$ & $\begin{array}{c}\text { Slot width, } \\
w_{s}(\mathrm{~mm})\end{array}$ & $\begin{array}{l}\text { Resonant } \\
\text { frequency } \\
\quad(\mathrm{GHz})\end{array}$ & Bandwidth $(\mathrm{MHz})$ & $\%$ bandwidth & Gain (dBi) & Rad. eff. (\%) \\
\hline \multirow[t]{5}{*}{16} & \multirow[t]{5}{*}{42.5} & 0.5 & 1.8688 & 82.1 & 4.4 & 2.0 & 91.3 \\
\hline & & 1 & 1.8848 & 98.8 & 5.2 & 2.1 & 93.0 \\
\hline & & 1.5 & 1.9008 & 112.9 & 5.9 & 2.0 & 92.0 \\
\hline & & 2 & 1.9168 & 118.6 & 6.2 & 2.1 & 93.8 \\
\hline & & 2.5 & 1.9264 & 124.7 & 6.5 & 2.2 & 95.1 \\
\hline
\end{tabular}




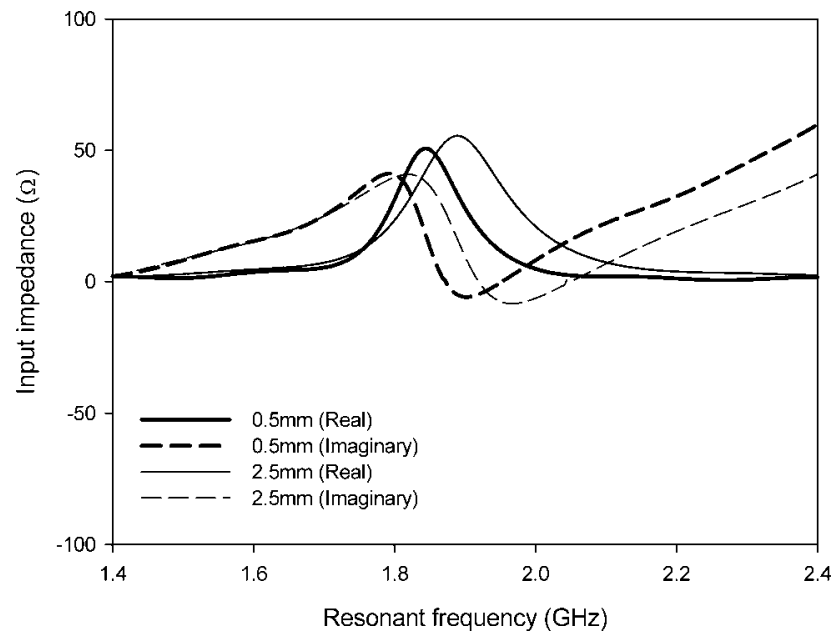

Figure 7 Simulated input impedance variation of the antenna with slot width $w_{s}$

All other dimensions of the antenna for these cases are given in Fig. 1. was observed when $L$ and $W$ are varied. In this case, the antenna gain remains a constant only because of the fact that bandwidth increases with decrease in groundplane dimension. However, the cross-polarisation in the $x z$-plane increases with decreases in the groundplane size. This is mainly because of diffraction from the edges of the small ground plane.

\subsection{Effect of slot width $\left(w_{s}\right)$ and tuning stub}

The bandwidth of the proposed CPW-fed slot-loop antenna depends mainly on the rectangular slot width $w_{s}$. The dependence of the impedance bandwidth on the slot width, $w_{s}$, is given in Fig. 5. The effect of slot width $\left(w_{s}\right)$ and slot length $(l)$ relative to the slot-loop width $(w)$ on the antenna bandwidth is illustrated. It is evident from the plots that the antenna bandwidth is a strong function of slot width $\left(w_{s}\right)$ rather than the slot length $(l)$. Thus, the slot width provides a useful tuning dimension for tailoring

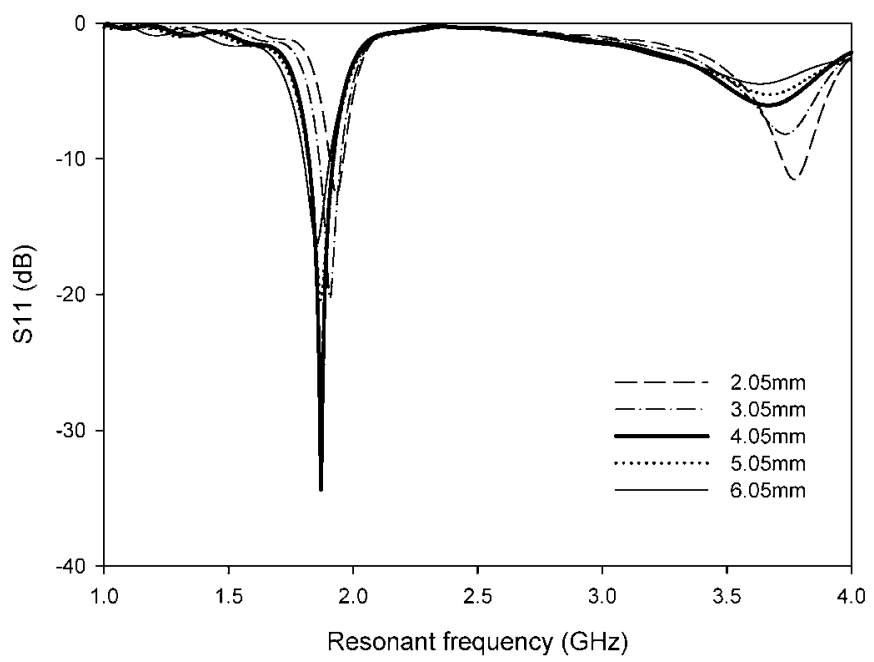

$a$

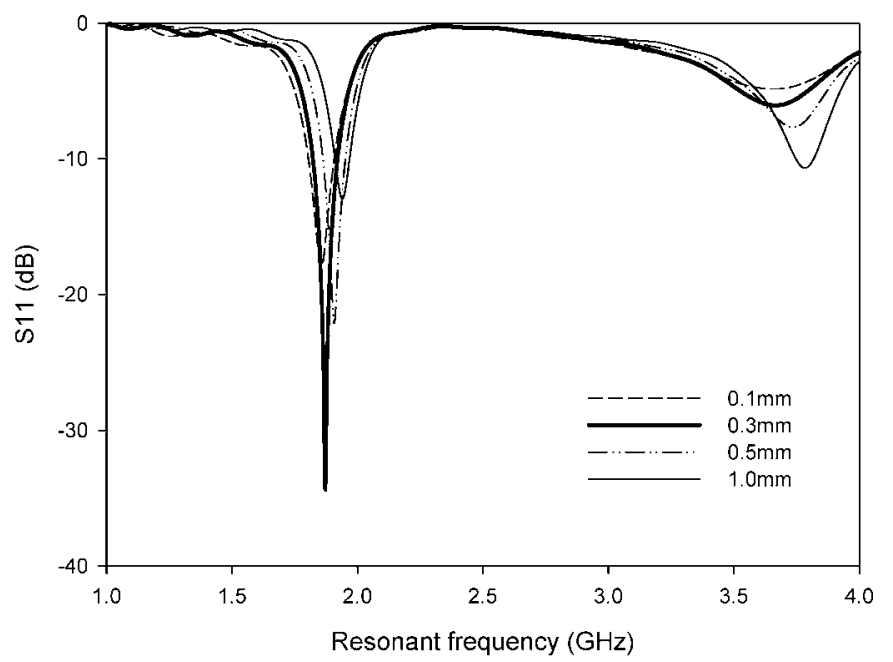

b

Figure 8 Variation of $S_{11}$ with change in tuning stub dimensions

$a$ Stub length, $t$

$b$ Top slot width, $d$

Table 4 Performance of the proposed CPW fed slot-loop antenna with change in tuning stub length

\begin{tabular}{|c|c|c|c|c|c|c|c|c|}
\hline $\begin{array}{l}\text { Slot-loop } \\
\text { width, w } \\
(\mathrm{mm})\end{array}$ & $\begin{array}{c}\text { Slot-loop length, } \\
\text { / (mm) }\end{array}$ & $\begin{array}{c}\text { Slot width, } \\
w_{s}(\mathrm{~mm})\end{array}$ & $\begin{array}{l}\text { Tuning stub } \\
\text { length, } t \\
\text { (mm) }\end{array}$ & $\begin{array}{c}\text { Resonant } \\
\text { frequency } \\
(\mathrm{GHz})\end{array}$ & $\begin{array}{l}\text { Bandwidth } \\
\text { (MHz) }\end{array}$ & $\%$ bandwidth & Gain (dBi) & $\begin{array}{l}\text { Rad. } \\
\text { eff. } \\
(\%)\end{array}$ \\
\hline \multirow[t]{5}{*}{16} & \multirow[t]{5}{*}{42.5} & \multirow[t]{5}{*}{1} & 2.05 & 1.9328 & 55.1 & 2.9 & 2.1 & 92.0 \\
\hline & & & 3.05 & 1.9073 & 86.4 & 4.5 & 2.0 & 91.5 \\
\hline & & & 4.05 & 1.8848 & 98.8 & 5.2 & 2.1 & 93.0 \\
\hline & & & 5.05 & 1.8720 & 102.1 & 5.5 & 2.1 & 93.1 \\
\hline & & & 6.05 & 1.8545 & 104.2 & 5.6 & 2.0 & 91.5 \\
\hline
\end{tabular}


the antenna bandwidth, once all other dimensions are optimised. A relatively small shift in resonant frequency is observed when the slot width is varied (Fig. 6). This is mainly because of the change in the effective slot-loop length with the variation of slot width. The results obtained are given in Table 3. In order to realise a very narrow bandwidth, the slot width $w_{s}$ must be as thin as possible. The change in input impedance of the antenna is plotted for different values of slot width in Fig. 7. A negligibly small impedance variation is observed with a change in $w_{s}$, from $0.5 \mathrm{~mm}$ to $2.5 \mathrm{~mm}$. As the input impedance shows negligible variation with the change in slot width, this bandwidth-controlling mechanism of the proposed design is less constrained.

The length of the CPW tuning stub can be adjusted to improve the input impedance matching for the antenna. Good matching can also be achieved by tuning the top slot width, $d$. This is evident from the return loss plots in Fig. 8. Both the gain and radiation efficiency remains unaffected with the change in $d$. The resonant frequency shows a slight shift because of the change in effective length of the slot with the top slot width. The electric fields are mainly concentrated at the top and bottom slot sections of the loop. From the simulation results, it can be seen that these sections are excited in phase. As observed in Table 4, the bandwidth shows some dependence on tuning stub length for smaller values, but for $t>4.05 \mathrm{~mm}$, it shows less reliance. No change in the omnidirectional radiation pattern is observed with changes in tuning stub length.

\section{Conclusion}

A novel design of a CPW-fed slot-loop antenna specifically made for narrowband omnidirectional operation has been presented. The typical broad bandwidth of slot-loop antennas is reduced to $2.9 \%$ and a good omnidirectional radiation pattern was achieved, in contrast to the usual bidirectional patterns of slot-loops. The proposed antenna has a gain of $2.1 \mathrm{dBi}$ with comparatively less crosspolarisation in both the principal planes. The design gives 93\% radiation efficiency. A good control of the antenna bandwidth was realised by varying the radiating slot width without significantly affecting the antenna input impedance or resonant frequency. Bandwidths in the range of 1.7$6.9 \%$ are achievable with good omnidirectional radiation characteristics.

\section{References}

[1] GEYI W.: 'Physical limitations of antenna', IEEE Trans. Antennas Propag., 2003, AP-51, pp. 873-878

[2] CHU L.J.: 'Physical limitations of omnidirectional antennas', J. Appl. Phys., 1948, 19, pp. 1163-1175
[3] PelE I., MAHE Y., ChOUSSEAUd A., TOUTAIN S., GARel P.y.: 'Antenna design with control of radiation pattern and frequency bandwidth', IEEE Antennas Propag. Soc. Int. Symp., 2004, 1, pp. $783-786$

[4] WANG J.J.H.: 'Fundamental bandwidth limitation for small antennas on a platform', IEEE International Workshop on Antenna Technology, Small Antennas and Novel Metamaterials, 2006, pp. 281-284

[5] BALANIS C.A.: 'Antenna theory: analysis and design', 2nd edn., Chapter 14, p. 722

[6] DAHLGREN J.W., DARIAN L.G.: 'Narrowband antenna challenges for airborne platforms'. IEEE Military Communications Conf., MILCOM 2001, Vol. 2, pp. $1275-1277$

[7] DIKOUNDOU E., YUKHANOV y.V.: 'Decoupling of aperture antennas with impedance structures'. International Conf. on Antenna Theory and Techniques, Sevastopol, Ukraine, 2003, pp. 117-120

[8] DNIDNI T.A., LEE H., LIM Y., RAO Q.: 'Wide-band highefficiency printed loop antenna design for wireless communication systems', IEEE Trans. Antennas Propag., 2005, AP-54, pp. 873-878

[9] Chaimool S., Kerdsumang S., AKKRAEAKTHALIN P., VIVEK V.: 'A broadband CPW-fed square slot antenna using loading metallic strips and a widened tuning stub'. International Symp. on Communications and Information Technologies, Sappom, Japan, 26-29 October 2004, pp. $730-733$

[10] LIN X.C., WANG L.T.: 'A broadband CPW-fed loop slot antenna with harmonic control', IEEE Antennas Wireless Propag. Lett., 2003, 2, pp. 323-325

[11] LIN C.C., CHUANG H.R.: 'A $2.4 \mathrm{GHz}$ planar printed antenna with omni-directional horizontally polarized pattern for WLAN applications'. 33rd European Microwave Conf., Munich, 2003, pp. 1275-1278

[12] RUDGE A.W., MILNE K., OLVER A.D., KNIGHT P.: 'The handbook of antenna design', IEEE electromagnetic waves series., 1982, pp. $32-33$

[13] GARG R., BHARTIA P., BAHL I., ITTIPIBOON A.: 'Microstrip antenna design handbook (Artech House)', pp. $441-488$

[14] CHEN J.S.: 'Dual-frequency annular-ring slot antennas fed by CPW feed and microstrip line feed', IEEE Trans. Antennas Propag., 2005, AP-53, pp. 569-571

[15] LIN X.-C., YU C.-C.: 'Dual-band CPW-fed hybrid antenna', Elect Lett., 2007, 43, (11), pp. 599-600 
[16] Behdad N., SARABANDI K.: 'Improved slot and wire loop antennas', IEE Proc.-Microw. Antennas Propag., 2006, 153, (3), pp. 287-292

[17] TSAI H.S., YORK R.A.: 'FDTD analysis of CPW-fed folded-slot and multiple-slot antennas on thin substrates', IEEE Trans. Antennas Propag., 1996, 44, (2), pp. 217-226
[18] LLORENS D., OTERO P., PENALOSA C.C.: 'Dual-band, single CPW port, planar-slot antenna', IEEE Trans. Antennas Propag., 2003, 51, (1), pp. 137-139

[19] LU S.W., YANG C.H., HSU P.: 'A CPW-fed slot-loop antenna with low cross-polarization radiation'. Asia-Pacific Microwave Conf., Sydney, Australia, 2000, pp. 1400-1402 